\title{
QUALIDADE DE LATOSSOLOS VERMELHOS E VERMELHO-AMARELOS SOB VEGETAÇÃO NATIVA DE CERRADO ${ }^{1}$
}

\author{
Raissa de Almeida Papa ${ }^{2}$, Marilusa Pinto Coelho Lacerda ${ }^{3}$, \\ Patrícia Maurício Campos ${ }^{2}$, Wenceslau J. Goedert ${ }^{3}$, Maria Lucrécia Gerosa Ramos ${ }^{3}$, Eiyti Kato
}

\begin{abstract}
RED AND RED-YELLOW OXISOLS QUALITY

UNDER NATIVE SAVANNAH VEGETATION

Soil quality can be defined as the capacity that the soil presents to perform its functions on ecosystems, being considered a good tool for studying and planning sustainable land use. This study aimed to describe the Red and Red-Yellow Oxisols quality under native Savannah vegetation, in order to establish reference values for their main attributes. The experiment was carried out at the Fazenda Água Limpa, Distrito Federal, Brazil, where the following soil quality attributes were evaluated: physical (soil density and porosity, aggregate stability, and flocculation index), chemical (cation exchange capacity, base sum and saturation, and organic matter content), and microbiological (microbial biomass carbon content and basal respiration). The results showed a great similarity among the soils attributes evaluated and provided the organization of radial graphics, with area delimitation defined as referential quality for all soils, which can be used for evaluating the natural equilibrium that takes place when these soils are submitted to diversified uses and agricultural managements.
\end{abstract}

KEY-WORDS: Soil quality; sustainability; natural ecosystem.

\section{INTRODUÇÃO}

O solo é formado por processos resultantes de fatores bióticos e abióticos, que determinam a sua constituição e o seu comportamento em ambiente natural, em equilíbrio. A interação e a intensidade destes fatores dão origem a solos com diferentes características, que permitem definir sua aptidão para o uso agrícola, dentre outros usos (Resende et al. 2007). Assim, as áreas nativas de Cerrado incorporadas ao processo produtivo agropecuário levam à ruptura do equilíbrio natural dos solos.

\section{RESUMO}

A qualidade do solo é definida como a capacidade de os solos exercerem suas funções nos ecossistemas, sendo considerada uma boa ferramenta para o estudo e planejamento de usos sustentáveis da terra. Este estudo teve como objetivo caracterizar a qualidade dos Latossolos Vermelhos (LV) e Vermelho-Amarelos (LVA), sob vegetação nativa de Cerrado, a fim de quantificar seus principais atributos referenciais. $\mathrm{O}$ trabalho foi desenvolvido na Fazenda Água Limpa (DF), onde foram analisados indicadores de qualidade de solo físicos (densidade e porosidade do solo, estabilidade de agregados e índice de floculação), químicos (capacidade de troca catiônica (CTC), soma de bases, saturação por bases (V) e teor de matéria orgânica) e microbiológicos (teor de carbono da biomassa microbiana e respiração basal). Semelhanças foram observadas nos atributos dos solos analisados e o estudo possibilitou a geração de gráficos radiais, com delimitação de área definida como de qualidade referencial, para os solos estudados, passíveis de serem utilizados na avaliação do desequilíbrio natural que ocorre quando estes solos são submetidos a usos e manejos agrícolas diversificados.

PALAVRAS-CHAVE: Qualidade do solo; sustentabilidade; ecossistema natural.

Uma estratégia para avaliar se um solo está sendo usado de modo sustentável baseia-se na adoção do enfoque de qualidade do solo (QS) proposto por Doran \& Parkin (1994), mas há dificuldades na seleção das propriedades do solo que devem ser avaliadas, bem como os valores que devem ser considerados como adequados ou ideais, uma vez que estes variam com o tipo de solo (Arshad \& Martin 2002). O conceito de qualidade de solo é baseado na premissa de que o manejo pode degradar, estabilizar ou aumentar as funções do ecossistema (Fransluebbers 2002). O uso do solo com práticas

1. Trabalho recebido em fev./2011 e aceito para publicação em dez./2011 (nº registro: PAT 13234/ DOI: 10.5216/pat.v41i4.13234).

2. Ministério da Agricultura, Pesca e Abastecimento, Brasília, DF, Brasil.

E-mails: raissapapa@gmail.com, patymauricio@gmail.com.

3. Universidade de Brasília, Faculdade de Agronomia e Medicina Veterinária, Brasília, DF, Brasil.

E-mails: marilusa@unb.br, goedert@unb.br, lucrecia@unb.br,kato@unb.br. 
adequadas de manejo contribuirá para que, a longo prazo, um novo equilíbrio seja atingido, resultando em solo com qualidade diferente daquela de solos sob vegetação natural.

Os indicadores mais frequentemente utilizados para avaliar a qualidade do solo têm sido os atributos que podem ser alterados, de forma lenta, pelo uso do solo, tais como densidade, porosidade total, resistência à penetração, grau de floculação, nível de agregação, teor de matéria orgânica e capacidade de troca catiônica (Plante \& McGill 2002, Dexter 2004).

Dentre os atributos microbiológicos, destacam-se o carbono da biomassa microbiana e a respiração basal, que são muito sensíveis às alterações que ocorrem no solo, tais como manejo e cultivo, além de alterações ambientais, como a umidade (Perez et al. 2004). A respiração basal é um indicativo da atividade microbiana do solo e representa o carbono prontamente mineralizável do solo (Alef \& Nannipieri 1995).

A avaliação destes atributos, em solos sob vegetação natural, tem sido adotada como alternativa, em estudos que visam a avaliar e monitorar a QS sob uso agropecuário, quando não se dispõe da definição de parâmetros ou valores dos atributos de QS considerados sustentáveis, para os solos em estudo sob uso antrópico.

Uma proposta de conjunto mínimo de indicadores para avaliar a QS em horizontes A de latossolos tropicais (região do Planalto Central Brasileiro), com textura argilosa e sob uso agrícola, foi apresentada por Goedert (2005), onde estão quantificados os níveis de sustentabilidade para atributos que têm sido mais adotados em pesquisas de avaliação da qualidade de solos sob uso agrícola, no Brasil.

Grandes modificações têm sido registradas, no Distrito Federal (DF), no uso e ocupação de terras, em função do crescimento populacional e desenvolvimento de atividades agrícolas. Muitas vezes, tem-se observado desenvolvimento agrícola sem planejamento de uso e manejo adequados, que visem à conservação da qualidade dos solos (Araújo et al. 2007).

Diante deste cenário, este trabalho objetivou avaliar atributos indicadores de qualidade de Latossolos Vermelhos e Latossolos Vermelho-Amarelos argilosos do Distrito Federal, sob vegetação nativa, a fim de definir parâmetros de qualidade natural ou referencial destes solos, que possam ser utilizados em estudos de avaliação da qualidade de solos sob uso agrícola, e comparar os parâmetros referenciais de
QS definidos com os propostos na literatura, também para solos sob uso agrícola.

\section{MATERIAL E MÉTODOS}

O estudo foi realizado em 2008, na Fazenda Água Limpa (FAL) da Universidade de Brasília (UnB), considerada, por meio da avaliação dos dados da literatura e atividades de campo, representativa da distribuição de Latossolos Vermelhos (LV) e Latossolos Vermelho-Amarelos (LVA) de textura argilosa, na paisagem do Distrito Federal (DF). A FAL localiza-se ao sul de Brasília, sendo delimitada pelas coordenadas $15^{\circ} 56^{\prime}$ a $15^{\circ} 59^{\prime}$ de latitude Sul e $47^{\circ} 55^{\prime}$ a $47^{\circ} 58^{\prime}$ de longitude Oeste.

Foram abertas oito trincheiras, para a descrição morfológica dos perfis selecionados para o estudo, assim como para a coleta de amostras para análises laboratoriais, segundo normas estabelecidas por Santos et al. (2005), sendo quatro de LV e quatro de LVA. Foram coletadas amostras na camada $0-10 \mathrm{~cm}$ (horizontes A) e amostras representativas dos horizontes $\mathrm{Bw}$, todas com três repetições, para a realização de análises químicas e físicas.

Para as análises microbiológicas, foram coletadas amostras, na camada $0-10 \mathrm{~cm}$, compostas por 5 subamostras, também com três repetições. A seleção das trincheiras foi realizada em função da distribuição destes solos na paisagem do DF, principalmente com relação à geomorfologia, que condiciona a ocorrência das diferentes classes de latossolos nesta região, além da associação com a vegetação nativa.

Foram selecionadas quatro unidades geomorfológicas representativas da distribuição dos perfis dos latossolos na paisagem da FAL, onde foram abertas duas trincheiras, em cada uma delas (uma de LV e uma de LVA). Estas unidades geomorfológicas foram denominadas Chapada Central e Chapada Centro-Oeste (C-W) - superfície geomorfológica de região de chapadas, com altitudes atingindo $1.300 \mathrm{~m}$, segundo Novaes Pinto (1994), onde os LV ocorrem no topo, enquanto os LVA ocorrem, preferencialmente, próximos às bordas das chapadas; e Dissecação Capetinga e Dissecação Taquara - superfície geomorfológica denominada Área de Dissecação Intermediária, com altitudes de até $1.050 \mathrm{~m}$ (Novaes Pinto 1994), estando, a primeira, na microbacia do Córrego Capetinga e a segunda na microbacia do Córrego Taquara, com desenvolvimento de LV nos interflúvios e LVA nas áreas de maior declividade. 
Como os solos estudados encontram-se sob vegetação nativa e correspondem a uma situação de equilíbrio natural, foi estabelecida uma avaliação que represente o grau de qualidade natural destes solos, denominada, neste trabalho, de qualidade referencial.

Foram avaliados os seguintes atributos dos LV e LVA estudados: físicos (textura, densidade do solo (Ds), densidade de partículas (Dp), porosidade total (PT), índice de floculação (IF) e diâmetro médio ponderado de agregados (DMP)), químicos (capacidade de troca catiônica (CTC), soma de bases (S), saturação por bases (V) e teor de matéria orgânica (MO)) e microbiológicos (carbono da biomassa microbiana (BM) e respiração basal (RB)), seguindo-se a proposta de Araújo et al. (2007), para latossolos do Distrito Federal.

A análise dos atributos de natureza física e química foi realizada segundo metodologias descritas em Embrapa (1997). As análises microbiológicas foram realizadas pelo método da fumigação e incubação (Jenkinson \& Powlson 1976, Alef \& Nannipieri 1995). Adicionalmente, foi avaliada a condição de percolação de água, nos perfis de LV e LVA, mediante análise do teor de umidade volumétrica, em amostras indeformadas de solo.

Com os dados dos principais atributos físicos (PT e IF), químicos (CTC e MO) e microbiológicos (RB e BM), considerados indicadores de qualidade dos horizontes A destes solos, foram gerados gráficos radiais, integrando os principais atributos avaliados para os Latossolos Vermelhos e Latossolos Vermelho-Amarelos, definindo áreas que correspondem aos limites de qualidade referencial destes solos. Os gráficos radiais foram elaborados utilizando-se as médias aritméticas simples dos resultados de cada indicador de qualidade. Tendo-se em vista que os valores apresentaram grandes variações na ordem de grandeza, valores originais de alguns atributos foram expressos em múltiplos decimais, de forma que todos ficassem inseridos na escala de 0 a 1 .

Posteriormente, foram organizados gráficos radiais, para comparar a qualidade dos horizontes A dos LV e LVA sob vegetação nativa com a de horizontes A de Latossolos sob cultivo, adotando-se o modelo proposto por Goedert (2005), para avaliar o grau de variação da QS natural ou referencial da QS sob uso sustentável.

\section{RESULTADOS E DISCUSSÃO}

Os trabalhos de campo permitiram observar a distribuição dos solos na paisagem, principal- mente com relação à geomorfologia, e variações na vegetação nativa associada. As unidades da paisagem selecionadas representam a distribuição dos Latossolos Vermelhos distróficos típicos (LV) e Latossolos Vermelho-Amarelos distróficos petroplínticos (LVA), no Distrito Federal. Nas unidades denominadas Chapada Central e Centro-Oeste, os LV ocorrem nos topos das chapadas, em relevo plano, associados à vegetação de Cerrado strictu sensu e cerradão, enquanto os LVA ocorrem nas bordas das chapadas, em declividade discretamente maior, com desenvolvimento de cerrado ralo, campo-cerrado e campo sujo. Nas unidades de Dissecação Capetinga e Taquara, os LV e LVA apresentam distribuição e associação com vegetação nativa similar à descrita anteriormente, porém em altitudes mais baixas, relacionadas à superfície geomorfológica da Área de Dissecação Intermediária (Novaes Pinto 1994).

Os dados das análises químicas e físicas são apresentados nas Tabelas 1 e 2, respectivamente. $\mathrm{Na}$ Tabela 3, encontram-se detalhadas as médias dos atributos considerados indicadores de qualidade, assim como os dados das análises microbiológicas.

A avaliação preliminar dos resultados, por intermédio da comparação entre os valores dos indicadores de qualidade do solo avaliados, permitiu observar que, sob vegetação nativa, os Latossolos Vermelhos e Vermelho-Amarelos apresentam qualidade de solo semelhante. Em termos de atributos físicos (Tabela 1), foram observados altos valores de porosidade total, índice de floculação e diâmetro médio ponderado, refletindo o elevado estado de estruturação e a alta permeabilidade destes solos, sob vegetação nativa, concordando com o dados obtidos por Araújo et al. (2007).

A principal diferença entre os solos estudados se refere às condições de percolação de água nos perfis, constatadas pelos valores de umidade na base de peso (U) (Tabela 1), que são sempre maiores nos LVA que nos LV, nos horizontes A e, particularmente, nos horizontes Bw. Como ambos possuem alta porosidade, a taxa de infiltração de água deveria ser semelhante, porém, os Latossolos Vermelho-Amarelos, geralmente, possuem, no horizonte $\mathrm{Bw}$, camadas de petroplintitas que prejudicam a drenagem interna. Tal fato é particularmente verificado nos períodos chuvosos, onde os LVA ficam com saturação de água, tal como constatado por Campos et al. (2010).

A oscilação do nível do lençol freático favorece a formação da goethita, em relação a hematita, 
Tabela 1. Análises físicas dos Latossolos Vermelho-Amarelos e Latossolos Vermelhos estudados (Brasília, DF, 2008).

\begin{tabular}{|c|c|c|c|c|c|c|c|c|c|}
\hline \multirow{2}{*}{ Perfis } & \multirow{2}{*}{$\begin{array}{c}\text { Unidade } \\
\text { geomorfológica }\end{array}$} & \multirow{2}{*}{ Horizonte } & Ds & $\mathrm{Dp}$ & PT & IF & $\mathrm{U}$ & DMP & Argila \\
\hline & & & $\mathrm{g} \mathrm{cm}^{-3}$ & $\mathrm{~g} \mathrm{~m}^{-3}$ & $\mathrm{~cm}^{3} \mathrm{~cm}^{-3}$ & $\%$ & $\mathrm{~g} \mathrm{~g}^{-1}$ & $\mathrm{~mm}$ & $\mathrm{~g} \mathrm{~kg}^{-1}$ \\
\hline \multicolumn{10}{|c|}{ Latossolos Vermelho-Amarelos distróficos petroplínticos - LVA } \\
\hline \multirow{2}{*}{ Perfil 1} & Chapada & A & 0,88 & 2,53 & 65,00 & 79,39 & 41,7 & 2,58 & 698,0 \\
\hline & Central & $\mathrm{Bw}$ & 0,96 & 2,50 & 61,00 & 55,38 & 48,4 & 1,19 & 607,1 \\
\hline \multirow{2}{*}{ Perfil 2} & Chapada & A & 0,98 & 2,47 & 60,00 & 80,34 & 50,4 & 1,61 & 514,0 \\
\hline & Centro-Oeste & $\mathrm{Bw}$ & 1,03 & 2,56 & 59,00 & 82,50 & 53,2 & 1,36 & 591,0 \\
\hline \multirow{2}{*}{ Perfil 3} & Dissecação & A & 0,87 & 2,38 & 66,00 & 50,89 & 34,3 & 2,60 & 675,1 \\
\hline & Capetinga & $\mathrm{Bw}$ & 0,99 & 2,56 & 61,00 & 94,61 & 39,0 & 1,51 & 743,4 \\
\hline \multirow{2}{*}{ Perfil 4} & Dissecação & $\mathrm{A}$ & 1,03 & 2,38 & 58,00 & 91,62 & 54,9 & 2,07 & 481,0 \\
\hline & Taquara & $\mathrm{Bw}$ & 0,90 & 2,44 & 62,00 & 54,42 & 64,7 & 1,60 & 604,9 \\
\hline \multicolumn{10}{|c|}{ Latossolos Vermelhos distróficos típicos - LV } \\
\hline \multirow{2}{*}{ Perfil 2} & Chapada & A & 0,78 & 2,50 & 69,00 & 80,81 & 33,1 & 2,25 & 825,5 \\
\hline & Central & $\mathrm{Bw}$ & 0,81 & 2,59 & 68,00 & 66,70 & 34,9 & 2,15 & 740,0 \\
\hline \multirow{2}{*}{ Perfil 4} & Chapada & A & 0,81 & 2,53 & 68,00 & 82,66 & 36,9 & 2,35 & 726,2 \\
\hline & Centro-Oeste & $\mathrm{Bw}$ & 0,90 & 2,44 & 62,00 & 87,82 & 34,2 & 2,36 & 882,0 \\
\hline \multirow{2}{*}{ Perfil 6} & Dissecação & A & 0,66 & 2,50 & 74,00 & 53,52 & 35,9 & 2,55 & 842,5 \\
\hline & Capetinga & $\mathrm{Bw}$ & 0,65 & 2,35 & 72,00 & 95,55 & 35,9 & 2,44 & 870,0 \\
\hline \multirow{2}{*}{ Perfil 8} & Dissecação & A & 0,90 & 2,44 & 63,00 & 68,43 & 28,8 & 2,64 & 746,7 \\
\hline & Taquara & $\mathrm{Bw}$ & 0,76 & 2,53 & 69,00 & 96,96 & 38,2 & 2,09 & 775,8 \\
\hline
\end{tabular}

$\mathrm{Ds}=$ densidade do solo; $\mathrm{Dp}=$ densidade das partículas; $\mathrm{PT}$ = porosidade total; $\mathrm{IF}$ = índice de floculação; $\mathrm{U}=$ umidade na base de peso ou gravimétrica; $\mathrm{DMP}=$ diâmetro médio ponderado (valor máximo de $3,00 \mathrm{~mm}$ ).

Tabela 2. Análises químicas dos Latossolos Vermelho-Amarelos e Latossolos Vermelhos estudados (Brasília, DF, 2008).

\begin{tabular}{|c|c|c|c|c|c|c|c|}
\hline \multirow{2}{*}{ Perfis } & \multirow{2}{*}{$\begin{array}{c}\text { Unidade } \\
\text { geomorfológica }\end{array}$} & \multirow{2}{*}{ Horizonte } & $\mathrm{pH}$ & CTC & $\mathrm{MO}$ & $\mathrm{S}$ & $\mathrm{V}$ \\
\hline & & & $\mathrm{H}_{2} \mathrm{O}$ & $\mathrm{cmol} \mathrm{kg}^{-1}$ & $\mathrm{~g} \mathrm{Kg}^{-1}$ & $\mathrm{cmol} \mathrm{kg}^{-1}$ & $\%$ \\
\hline \multicolumn{8}{|c|}{ Latossolos Vermelho-Amarelos distróficos petroplínticos - LVA } \\
\hline \multirow{2}{*}{ Perfil 1} & Chapada & $\mathrm{A}$ & 5,70 & 2,86 & 41,20 & 0,14 & 4,84 \\
\hline & Central & Bw & 6,00 & 1,03 & - & 0,12 & 11,58 \\
\hline \multirow[b]{2}{*}{ Perfil 3} & Chapada & A & 5,30 & 3,84 & 42,20 & 0,54 & 14,16 \\
\hline & Centro-Oeste & $\mathrm{Bw}$ & 5,70 & 0,45 & - & 0,12 & 27,06 \\
\hline \multirow{2}{*}{ Perfil 5} & Dissecação & A & 5,10 & 7,80 & 49,00 & 0,21 & 2,68 \\
\hline & Capetinga & Bw & 5,40 & 2,91 & - & 0,19 & 6,48 \\
\hline \multirow{2}{*}{ Perfil 7} & Dissecação & A & 5,80 & 1,86 & 50,12 & 0,13 & 6,93 \\
\hline & Taquara & $\mathrm{Bw}$ & 6,20 & 0,52 & - & 0,11 & 21,58 \\
\hline \multicolumn{8}{|c|}{ Latossolos Vermelhos distrófico típicos - LV } \\
\hline \multirow{2}{*}{ Perfil 2} & Chapada & $\mathrm{A}$ & 5,30 & 8,35 & 47,00 & 0,51 & 6,11 \\
\hline & Central & $\mathrm{Bw}$ & 5,10 & 4,58 & - & 0,37 & 8,00 \\
\hline \multirow{2}{*}{ Perfil 4} & Chapada & $\mathrm{A}$ & 5,20 & 7,91 & 44,50 & 0,32 & 4,05 \\
\hline & Centro-Oeste & $\mathrm{Bw}$ & 5,20 & 3,57 & - & 0,27 & 7,46 \\
\hline \multirow{2}{*}{ Perfil 6} & Dissecação & $\mathrm{A}$ & 5,30 & 8,94 & 42,50 & 0,28 & 3,13 \\
\hline & Capetinga & $\mathrm{Bw}$ & 3,80 & 4,66 & - & 0,37 & 7,89 \\
\hline \multirow{2}{*}{ Perfil 8} & Dissecação & $\mathrm{A}$ & 5,50 & 4,86 & 39,30 & 0,24 & 4,85 \\
\hline & Taquara & $\mathrm{Bw}$ & 3,30 & 3,31 & - & 0,50 & 15,18 \\
\hline
\end{tabular}

$\mathrm{CTC}=$ capacidade de troca catiônica; $\mathrm{MO}$ = matéria orgânica; $\mathrm{S}=$ soma de bases; $\mathrm{V}=$ saturação por bases.

e diminui a relação gibbsita/caulinita dos LVA(Barbosa et al. 2009, Campos et al. 2010), podendo ser a responsável pela diminuição dos agregados nos LVA, com camadas de petroplintitas nos horizontes $\mathrm{Bw}$, apresentando, portanto, valores de DMP, nos horizontes $\mathrm{Bw}$, inferiores aos do horizonte $\mathrm{A}$, assim como dos horizontes A e Bw dos LV.

A menor relação gibbsita/caulinta também pode contribuir para o decréscimo da estabilidade dos agregados, nos horizontes Bw dos LV, como observado por Lima \& Anderson (1997). Este comportamento pode comprometer o potencial de uso agrícola dos LVA, tal como demonstra a vegetação nativa diferenciada nestes solos, com desenvolvimento de cerrado ralo, campo-cerrado e campo sujo, enquanto, nos LV, a vegetação nativa associada é o Cerrado strictu sensu ou cerradão. 
Tabela 3. Valores médios reais e transformados dos atributos utilizados para construção dos gráficos radiais (Brasília, DF, 2008).

\begin{tabular}{|c|c|c|c|c|c|c|c|c|c|c|c|c|}
\hline \multirow{3}{*}{ Solo } & \multirow{3}{*}{ Horizonte } & \multicolumn{3}{|c|}{ Análises físicas } & \multicolumn{4}{|c|}{ Análises químicas } & \multicolumn{4}{|c|}{ Análises microbiológicas } \\
\hline & & PT & IF & IF $\times 10^{-2}$ & CTC & $\mathrm{CTC} \times 10^{-1}$ & MO & $\mathrm{MO} \times 10^{-2}$ & $\mathrm{RB}$ & $\mathrm{RB} \times 5.10^{-2}$ & $\mathrm{BM}$ & $\mathrm{BM} \times 10^{-3}$ \\
\hline & & $\mathrm{cm}^{3} \mathrm{~cm}^{-3}$ & \multicolumn{2}{|c|}{ - dag $\mathrm{kg}^{-1}-$} & \multicolumn{2}{|c|}{$-\mathrm{cmol}_{\mathrm{c}} \mathrm{dm}^{-3}-$} & \multicolumn{2}{|c|}{$\mathrm{g} \mathrm{kg}^{-1}$} & \multicolumn{4}{|c|}{$\mathrm{mg} \mathrm{C} \mathrm{kg}^{-1}$} \\
\hline LV & A & 0,61 & 71,36 & 0,71 & 8,31 & 0,83 & 43,30 & 0,43 & 16,65 & 0,83 & 506,58 & 0,51 \\
\hline LVA & $\mathrm{A}$ & 0,64 & 75,56 & 0,76 & 6,25 & 0,63 & 45,63 & 0,46 & 14,31 & 0,72 & 649,36 & 0,65 \\
\hline
\end{tabular}

$\mathrm{PT}=$ porosidade; $\mathrm{IF}=$ índice de floculação $\mathrm{CTC}=$ capacidade de troca catiônica; $\mathrm{MO}=$ matéria orgânica; $\mathrm{RB}=$ respiração basal; $\mathrm{BM}=$ carbono da biomassa microbiana.

Em relação aos indicadores físicos propostos por Goedert (2005), que representam níveis de sustentabilidade, na camada superficial (horizonte A) de Latossolos tropicais de textura argilosa, sob uso agrícola (Tabela 4), as características físicas obtidas nos solos estudados são compatíveis. Pela comparação com os dados da Tabela 1 e dados médios dos horizontes A dos LV e LVA, sob vegetação nativa, apresentados na Tabela 3, pode-se constatar que os solos estudados possuem valores médios de densidade do solo inferiores a $1,0 \mathrm{~g} \mathrm{~cm}^{-3}$, porosidade total superior a $0,60 \mathrm{~cm}^{3} \mathrm{~cm}^{-3}$, índice de floculação superior a $50 \%$ e alta estabilidade de agregados, sendo, portanto, de baixa erodibilidade e alta permeabilidade e aeração, confirmando o relato de Dedecek et al. (1986).

A estrutura destes solos, quando intensamente mecanizados, pode ser danificada, levando à redução da porosidade e, consequentemente, à formação de uma camada compactada (Araújo et al. 2007). O manejo destes solos deve ser adequado, para que estas características físicas não se alterem drasticamente, ocasionando a degradação do solo. A densidade do solo, dependendo do uso, pode ser aumentada e o volume de poros diminuído (Souza et al. 2005), principalmente em sistema de plantio convencional, quando comparado ao sistema plantio direto, na região do Cerrado (Silva et al. 2001). Verifica-se, também, aumento da resistência à penetração no solo e diminuição do teor de matéria orgânica (Souza \& Alves 2003), além do decréscimo do carbono da biomassa microbiana do solo (Perez et al. 2004 e 2005).

Embora o teor de MO seja elevado, o valor de CTC varia entre baixo e médio, reflexo, principalmente, do baixo pH (Tabela 2). A saturação de bases é muito baixa, face ao elevado grau de acidez total, indicando a necessidade de correção desta acidez, para melhorar a qualidade destes solos. Nas propriedades químicas, observa-se que os valores médios da CTC e saturação de bases estão abaixo dos limites estabelecidos por Goedert (2005), cujos

Tabela 4. Proposta de conjunto mínimo de indicadores ou atributos (Goedert 2005), para avaliar a qualidade do solo sob uso agrícola e de seus valores ou níveis de sustentabilidade, determinados na camada superficial de Latossolos tropicais.

\begin{tabular}{|c|c|}
\hline Indicador ou atributo & Valor ou nível de sustentabilidade ${ }^{(1)}$ \\
\hline Densidade do solo (Ds) & $<1,0 \mathrm{~g} \mathrm{~cm}^{-3}$ \\
\hline Porosidade total (PT) & $>0,60 \mathrm{~cm}^{3} \mathrm{~cm}^{-3}$ \\
\hline Resistência mecânica à penetração (Rp) & $<1,0 \mathrm{MPa}$ \\
\hline Grau de floculação (Gf) & $>50 \%$ \\
\hline Teor de matéria orgânica (MO) & $\begin{array}{l}\text { Textura argilosa: }>40 \mathrm{~g} \mathrm{~kg}^{-1} \\
\text { Textura média: }>30 \mathrm{~g} \mathrm{~kg}^{-1} \\
\text { Textura arenosa: }>20 \mathrm{~g} \mathrm{~kg}^{-1}\end{array}$ \\
\hline Capacidade de troca catiônica (CTC) & $\begin{array}{l}\text { Textura argilosa: }>10 \mathrm{cmol}_{\mathrm{c}} \mathrm{dm}^{-3} \\
\text { Textura média: }>7 \mathrm{cmol}_{\mathrm{c}} \mathrm{dm}^{-3} \\
\text { Textura arenosa: }>4 \mathrm{cmol}_{\mathrm{c}} \mathrm{dm}^{-3}\end{array}$ \\
\hline Saturação por bases (V) & $>40 \%$ \\
\hline Carbono da biomassa microbiana (Cmic) & $>200 \mathrm{mg} \mathrm{C} \mathrm{kg}^{-1}$ \\
\hline Respiração basal (Rmic) & $>10 \mathrm{mg} \mathrm{C} \mathrm{kg}^{-1} \mathrm{dia}^{-1}$ \\
\hline
\end{tabular}

(1) Avaliação realizada na camada subsuperficial, em solo com umidade próxima à capacidade de campo. 
valores considerados sustentáveis são superiores a $10 \mathrm{cmol}_{\mathrm{c}} \mathrm{dm}^{-3}$ e $40 \%$, respectivamente. Estes dados se justificam pela baixa atividade da fração argila dos latossolos nativos estudados, em relação aos solos sob usos agrícolas, que foram manejados quimicamente, atividade necessária, nestes solos, em função da alta acidez, toxidez de $\mathrm{Al}$ e deficiência de nutrientes (Tabela 4).

A média dos teores de matéria orgânica encontrada nos horizontes A dos Latossolos Vermelhos foi de 43,30 $\mathrm{g} \mathrm{kg}^{-1}$ e a dos Latossolos Vermelho-Amarelos foi de 45,63 $\mathrm{g} \mathrm{kg}^{-1}$, ambas superiores ao valor de $40 \mathrm{~g} \mathrm{~kg}^{-1}$, proposto por Goedert (2005). A matéria orgânica, nos LVA, foi maior que nos LV, provavelmente em função da saturação sazonal de água, que ocorre nos Latossolos Vermelho-Amarelos e que pode dificultar a decomposição da matéria orgânica.

As propriedades microbiológicas dos solos estudados estão apresentadas em valores médios na Tabela 3, em função da pequena variação verificada nos perfis avaliados, estando em níveis adequados, de acordo com a proposta feita por Goedert (2005), com média de respiração basal superior a $10 \mathrm{mg} \mathrm{C} \mathrm{kg}{ }^{-1} \mathrm{dia}^{-1} \mathrm{e}$ média de biomassa microbiana superior a $200 \mathrm{mg} \mathrm{C} \mathrm{kg}^{-1}$, em ambos os solos. Estes valores resultam da diversidade de materiais vegetais existentes, que geram um substrato com materiais orgânicos em diferentes graus de decomposição, por se tratarem de solos sob vegetação nativa (D'Andréa et al. 2002), representando solos bem estruturados e com maiores teores de matéria orgânica que os solos cultivados (Alvarenga et al. 1999, Fialho et al. 2006 e 2008).

Os gráficos radiais de qualidade referencial elaborados com os dados transformados (Tabela 3), para os horizontes A dos LV e LVA (Figura 1A), sob vegetação nativa, definem os limites de qualidade referencial destes solos, servindo como base de comparação para os solos sob uso agropecuário. Verifica-se que estes solos apresentam um padrão de qualidade referencial similar. Estes gráficos radiais também permitem a visualização e identificação do indicador de qualidade (físico, químico ou microbiológico) que está ocasionando o desequilíbrio, em função do uso ao qual o solo encontra-se submetido, permitindo avaliar o sistema de manejo adotado.

Os parâmetros de qualidade referencial ou equilíbrio natural dos LV e LVA, ambos de textura argilosa, representativos do Distrito Federal, estabelecidos neste trabalho, oferecem uma metodologia expedita para a avaliação das alterações da qualidade dos solos sob usos e manejos agrícolas diversificados, em relação aos limites considerados referenciais, ou seja, permite avaliar o grau de desequilíbrio
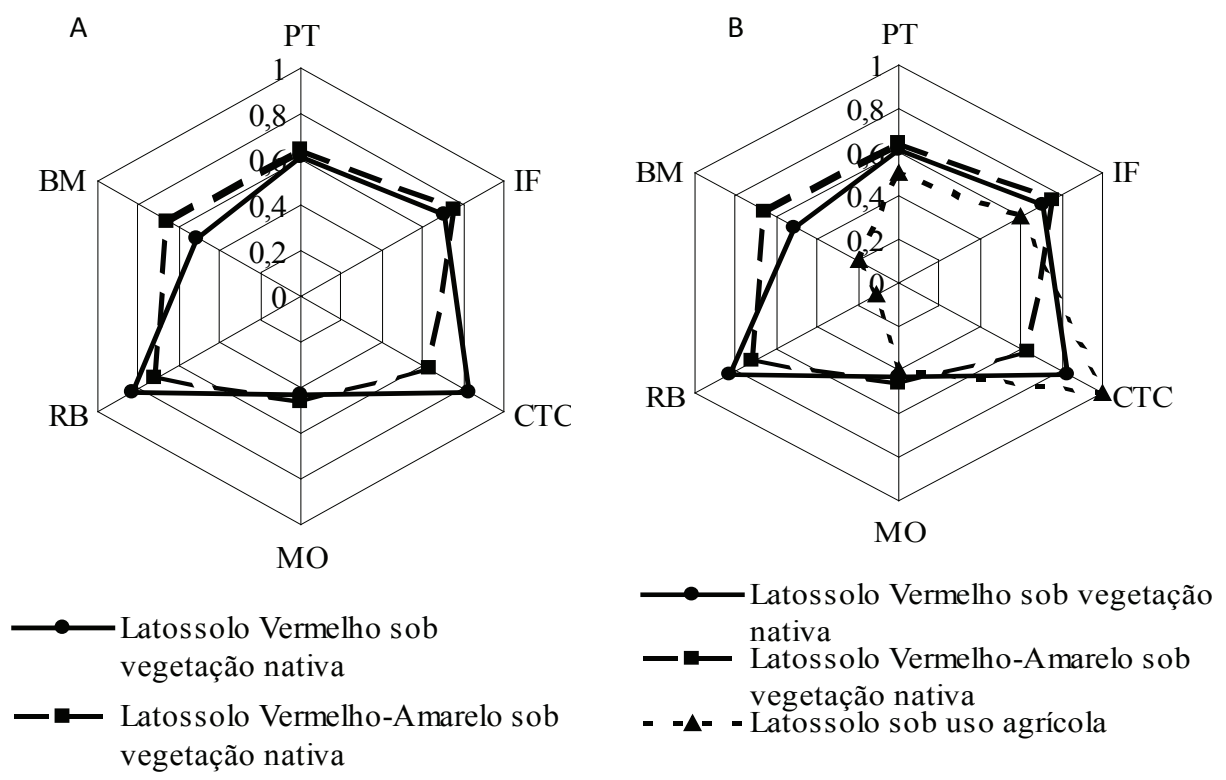

Figura 1. Diagrama comparativo de qualidade de LV e LVA (camada 0-10 cm), sob vegetação nativa do Cerrado (A), e diagrama comparativo de qualidade de solo (camada 0-10 cm) dos LV e LVA, sob vegetação nativa do Cerrado e latossolos sob uso agrícola (B) (Brasília, DF, 2008). PT: porosidade total; IF: índice de floculação; CTC: capacidade de troca catiônica; MO: matéria orgânica; RB: respiração basal; BM: carbono da biomassa microbiana. 
provocado pelo uso agrícola. Para avaliar se o solo alcançou novo equilíbrio ou condições sustentáveis, quando submetido a atividades agrícolas, pode-se utilizar a proposta de Goedert (2005), por meio da análise dos limites dos indicadores de qualidade do solo, em sistemas de produção agrícola considerados sustentáveis.

Com o intuito de comparar os valores de qualidade de solo sob vegetação nativa com os valores de sustentabilidade de alguns indicadores de qualidade do solo sob uso agrícola, segundo proposto por Goedert (2005) (Tabela 4), estes foram inseridos no mesmo gráfico radial dos horizontes A dos latossolos estudados (Figura 1B). Pelos gráficos, percebe-se que o Latossolo Vermelho e o Latossolo Vermelho-Amarelo (Figura 1B), ambos em equilíbrio natural, apresentam valores muito semelhantes aos dos latossolos sob uso agrícola sustentável, tendo-se em vista que os polígonos formados são de magnitude e formato similares.

Comparando-se os valores individuais dos atributos, observa-se que o uso do solo, para fins agrícolas, tende a diminuir os índices para os atributos físicos e microbiológicos. Isto é resultante, principalmente, do trabalho mecânico do solo (Perez et al. 2004) e da diminuição da diversidade de espécies vegetais sob cultivo. Já para a CTC, espera-se aumento dos índices, tendo-se em vista os efeitos da calagem no $\mathrm{pH}$ do solo e no surgimento de cargas negativas variáveis.

Os gráficos propostos neste trabalho podem ser usados para distinguir quando os solos ocupados por atividades agrícolas estão sendo manejados corretamente ou não, uma vez que os limites de sustentabilidade, sob uso agrícola, se aproximam dos limites do equilíbrio natural dos LV e LVA de textura argilosa, de ocorrência no Distrito Federal.

Para a avaliação do uso e manejo de latossolos do Distrito Federal, com a utilização dos gráficos radiais elaborados, os resultados dos atributos de um solo a ser avaliado são plotados nos gráficos correspondentes, em relação à classe de solo e horizonte pedogenético. Se os gráficos apresentarem área geométrica próxima à determinada pelos limites de equilíbrio natural dos gráficos radiais dos solos correspondentes, o manejo do solo avaliado está sendo feito de maneira adequada, conservando a sua qualidade referencial. Caso contrário, o solo estará sendo mal utilizado, indicando a necessidade de mudanças nas práticas e manejo adotados.

\section{CONCLUSÕES}

1. Os padrões de qualidade referencial dos Latossolos Vermelhos e Latossolos Vermelho-Amarelos de textura argilosa não permitiram diferenciação entre os mesmos, sob vegetação nativa, no Distrito Federal.

2. Constatou-se que os Latossolos Vermelho-Amarelos apresentam condições de percolação de água dificultada, em relação aos Latossolos Vermelhos, em função da ocorrência de camadas de petroplintitas, nos horizontes $\mathrm{Bw}$, as quais podem comprometer o seu potencial de uso agrícola.

3. Os gráficos de qualidade referencial dos Latossolos Vermelhos e Latossolos Vermelho-Amarelos sob vegetação nativa podem ser aplicados para avaliar o desequilíbrio natural da qualidade dos LV e LVA ocupados por atividades agrícolas diversificadas, no Distrito Federal.

4. Os valores de qualidade referencial dos Latossolos estudados sob vegetação nativa foram semelhantes aos níveis de sustentabilidade dos atributos de qualidade dos Latossolos sob uso agrícola determinados por Goedert (2005), principalmente com relação aos atributos físicos e microbiológicos.

\section{REFERÊNCIAS}

ALEF, K.; NANNIPIERI, P. Methods in applied soil microbiology and biochemistry. London: Academic Press, 1995.

ALVARENGA, M. I. N.; SIQUEIRA, J. O.; DAVIDE, A. C. Teor de carbono, biomassa microbiana, agregação e micorrizas em solos de Cerrado com diferentes usos. Ciência e Agrotecnologia, Lavras, v. 23, n. 3, p. 617-625, 1999.

ARAÚJO, R.; GOEDERT, W. J.; LACERDA; M. P. C. Qualidade de um solo sob diferentes usos e sob Cerrado nativo. Revista Brasileira de Ciência do Solo, Viçosa, v. 31, n. 1, p. 1099-1108, 2007.

ARSHAD, M. A.; MARTIN, S. Identifying critical limits for soil quality indicators in agro-ecosystems. Agricultural Ecosystems and Environment, Zürich, v. 88, n. 2, p. 153160, 2002.

BARBOSA, I. O; LACERDA, M. P. C.; BILICH, M. R. Relações pedomorfogeológicas nas chapadas elevadas do Distrito Federal. Revista Brasileira de Ciência do Solo, Viçosa, v. 33, n. 5, p. 1373-1383, 2009. 
CAMPOS, P. M. et al. Drenagem interna como fator de diferenciação de latossolos do Distrito Federal. Pesquisa Agropecuária Brasileira, Brasília, DF, v. 45, n. 3, p. 306314, 2010.

D'ANDRÉA, A. F. et al. Atributos biológicos indicadores da qualidade do solo em sistemas de manejo na região do Cerrado do sul do Estado de Goiás. Revista Brasileira de Ciência do Solo, Viçosa, v. 26, n. 4, p. 913-923, 2002.

DEDECEK, R. A.; RESCK, D. V. S.; FREITAS JÚNIOR, E. Perdas de solo, água e nutrientes por erosão em Latossolo Vermelho-Escuro dos Cerrados em diferentes cultivos sob chuva natural. Revista Brasileira de Ciência do Solo, Viçosa, v. 10, n. 3, p. 265-272, 1986.

DEXTER, A. R. Soil physical quality: part I. Theory, effects of soil texture, density and organic matter, and effects on root growth. Geoderma, Amsterdam, v. 120, n. 3-4, p. 201-214, 2004.

DORAN, J. W.; PARKIN, T. B. Defining and assessing soil quality. In: DORAN, J. M. et al. (Eds.). Defining soil quality for sustainable environment. Madison: Soil Science Society of America, 1994. p. 3-21.

EMPRESA BRASILEIRA DE PESQUISA AGROPECUÁRIA (Embrapa). Centro Nacional de Pesquisa de Solos. Manual de métodos de análise de solo. 2. ed. Rio de Janeiro: Embrapa CNPS, 1997.

FIALHO, J. S. et al. Indicadores da qualidade do solo em áreas sob vegetação natural e cultivo de bananeiras na Chapada do Apodi - CE. Revista Ciência Agronômica, Fortaleza, v. 37, n. 3, p. 250-257, 2006.

FIALHO, J. S. et al. Indicadores da qualidade do solo, em sistema de rotação, na Chapada do Apodi - CE. Revista Ciência Agronômica, Fortaleza, v. 39, n. 3, p. 353-361, 2008.

FRANZLUEBBERS, A. J. Soil organic matter stratification ratio as an indicator of soil quality. Soil \& Tillage Research, Amsterdam, v. 66, n. 2, p. 95-106, 2002.

GOEDERT, W. J. Qualidade do solo em sistemas de produção agrícola. In: CONGRESSO BRASILEIRO DE CIÊNCIA DO SOLO, 30., 2005, Recife. Anais... Recife: SBCS, 2005. 1 CD-ROM.

JENKINSON, D. S.; POWLSON, D. S. The effects of biocidal treatments on metabolism in soil: V. A method for measuring soil biomass. Soil Biology and Biochemistry, Brisbane, v. 8, n. 3, p. 209-213, 1976.
LIMA, J. M.; ANDERSON, S. J. Agregation and agragate size effects on extractable iron and aluminum in two hapludox. Soil Science Society of America Journal, Madison, v. 61, n. 3, p. 965-970, 1997.

NOVAES PINTO, M. Caracterização geomorfológica do Distrito Federal. In: NOVAES PINTO, M. (Org.). Cerrado: caracterização, ocupação e perpectivas. Brasília, DF: Ed. da UnB, 1994. p. 285-320.

PLANTE, A. F.; McGILL, W. G. Soil aggregate dynamics and the retention of organic matter in laboratory-incubated soil with differing simulated tillage frequencies. Soil \& Tillage Research, Amsterdam, v. 66, n. 1, p. 79-92, 2002.

PEREZ, K. S. S.; RAMOS, M. L. G.; McMANUS, C. Carbono da biomassa microbiana em solo cultivado com soja, sob diferentes sistemas de manejo nos Cerrados. Pesquisa Agropecuária Brasileira, Brasília, DF, v. 39, n. 6, p. 567-573, 2004.

PEREZ, K. S. S.; RAMOS, M. L. G.; McMANUS, C. Nitrogênio da biomassa microbiana em solo cultivado com soja, sob diferentes sistemas de manejo, nos Cerrados. Pesquisa Agropecuária Brasileira, Brasília, DF, v. 40, n. 2, p. 137-144, 2005.

RESENDE, M. et al. Pedologia: base para distinção de ambientes. Viçosa: NEPUT, 2007.

SANTOS, R. D. et al. Manual de descrição e coleta de solos no campo. 5. ed. Viçosa: SBCS, 2005.

SILVA, G. de M. et al. Caracterização físico-hídrica em um Latossolo Vermelho perférrico submetido a dois sistemas de manejo do solo. Pesquisa Agropecuária Tropical, Goiânia, v. 31, n. 2, p. 127-131, 2001.

SOUZA, E. D.; CARNEIRO, M. A. C.; PAULINO, H. B. Atributos físicos de um Neossolo quartzarênico e um Latossolo Vermelho sob diferentes sistemas de manejo. Pesquisa Agropecuária Brasileira, Brasília, DF, v. 40, n. 11, p. 1135-1139, 2005.

SOUZA, Z. M. de; ALVES, M. C. Propriedades físicas e teor de matéria orgânica em um Latossolo Vermelho de Cerrado sob diferentes usos e manejos. Acta Scientiarum Agronomy, Maringá, v. 25, n. 1, p. 27-34, 2003. 